\title{
REMOVAL OF FERRIC IONS (Fe+3) FROM NEUTRAL SOLUTIONS USING MODIFIED CHITOSAN
}

\author{
Magdy A. Wassel, Rabie S. Farg, Hassan A. Shehata, Aamal M. Anwar* and Hussein A. Mohamed \\ Chemistry department, Faculty of Science, Al-Azhar University, Cairo, Naser City, Egypt. \\ Crosponding auther: Prof. Magdy A. Wassel, \\ Mobil no:+2001280662520; Fax:+200233371168 \\ * Central Laboratories of the Egyptian Mineral Resources Authority, Cairo, Egypt.
}

\begin{abstract}
The object of this study is to assess the removal of Fe(III) ions from aqueous solutions onto modified chitosan. The effect of various parameters has been investigated by the following batch adsorption technique. The various variables studied include initial concentration of the adsorbate, agitation time, adsorbent dosage, kinetics, influence of temperature. The experimental data was fit well to the Freundlich isotherm. Thermodynamic parameters such as $\Delta \mathrm{H}, \Delta \mathrm{S}$ and $\Delta \mathrm{G}$ were calculated, indicating that the adsorption was spontaneous and endothermic nature.
\end{abstract}

\section{Keywords}

Removal; Adsorption; Fe(III); Chitosan and Adsorption Isotherm.

\section{Council for Innovative Research}

Peer Review Research Publishing System

Journal: Journal of Advances in Chemistry

Vol. 12, No. 2

editor@cirjac.com

www.cirjac.com 


\section{INTRODUCTION}

Heavy metals are one of the important categories of water pollutants, which are toxic for humans' through the feodchain pyramid. Heavy metal ions existing in aqueos waste streams of various industries such as: metal plaing, mining operations, battery manufacturing, and tannery fabrication are posing serious impacts on the health of human and animals [1].

Ground water and some water from bottom anoxic zones of reservoirs often contain iron and manganese ions or their complexes with natural organic malter. In conventional treatment, the oxidants such as oxygen, chlorine, ozone, or potassium permanganate. The chemistry of oxidation becomes complicated when background species such as phosphate and fulvic acid are involved, so that the oxidation of ferrous ion $\mathrm{Fe}(\mathrm{II})$, that can be normormally readily oxidized is retarded [2].

Microporous chitosan (CS) membranes were directly prepared by extraction of poly (ethylene glycol) (PEG) from CS/PEG blend membrane and were examined for iron and manganese ions removal from aqueous solutions. The different variables affecting the adsorption capacity of membranes such as contact time, $\mathrm{pH}$ of sorption medium, and initial ion concentration in the feed solution were investigated on a batch adsorption basis [3].

Removal and preconcentration of lead(II), copper(II), chromium(III) and iron(III) from wastewaters were investigated and explored. Three new alumina adsorbents of acidic, neutral and basic nature (I-III) were synthesized via physical adsorption and surface loading of 1-nitroso-2-naphthol as a possible chelating ionexchange. The modified alumina adsorbents are characterized by strong thermal stability as well as resistance to acidic medium leaching processes [5].

Moreover, heavy metals are often detected in wastewaters as a result of industrial activities. Heavy metals are known for their non-biodegradability and accumulation in living systems, causing serious diseases and disorders [6] Adsorption, on the order hand, is one of the most recommended phyisco-chemical treatment processes that is commonly used and aqueous solution. In addition process is well recognized as one of the most efficient methods for removal of heavy metals from their matrices. Adsorption is mainly based on the utilization of solid adsorbents from their organic, inorganic, biological or low cost materials [7, 8].

Chitosan, as a natural polysaccharide, has reactive amino and hydroxyl groups in its linear polyglucasamine chains, can be used to functionalize and modify. However, conventional modification method using single crosslinking with glutaraldehyde generally leads to decrease of functional group $\left(-\mathrm{NH}_{2}-\right)$ and loading capacity, its interested to prepare multifunctional chitosan-X. which used in many applications such as water treatment by using diethylene triamine penta actic acid (DTPA) with sufficient number of carboxyl groups on the backbones, is a commonly used as chelating agent for heavy metal. The preparation of modified chitosan investigated by IR, XRD, SEM and also mechanical properties which determined and comparative adsorption of some metal ions from aqueous solution, kinetics and thermodynamics of single system were studied [9].

\section{2-EXPERIMENTAL SECTION}

\section{1- Materials}

Chitosan (MW 5000 Daltons) was purchased from Tako Kasei Kogyo CO. Ltd., Japan and used as received. Starch $\left(\mathrm{C}_{6} \mathrm{H}_{10} \mathrm{O}_{5}\right)_{n}$ soluble GR was purchased from Merch chemicals India. Glutraldehyde $\left(\mathrm{C}_{5} \mathrm{H}_{8} \mathrm{O}_{2}\right)(\mathrm{MW}$ $100.12 \mathrm{gm}$ and density $1.13 \mathrm{Kg} / \mathrm{lit}$ ) was purchased from central Drug House, New Delhi, India. Sodium hexameta phosphate, a physical crosslinker of starch, was purchased from Pioneer chemical CO. New Delhi. Other chemical were of analytical grade.

\section{2- Preparation of modified chitosan crosslinked beads:}

$20 \mathrm{ml}$ of $2 \%$ acetic acid solution (in water) was taken in a beaker and a known quantity of chitosan was added slowly under stirring condition followed by stirring for about $2 \mathrm{hrs}$. A starch solution was prepared separately by dissolving a known quantity of starch in $10 \mathrm{ml}$ of water. The prepared starch solution was added into chitosan solution under stirring conditions and mixed together for $3 \mathrm{hrs}$ at room temperature. The prepared mixture was kept at room temperature $\left(20^{\circ} \mathrm{C}\right)$ over night.

Sodium hydroxide-methanol $(1: 20 \mathrm{w} / \mathrm{w})$ solution was prepared chitosan and starch solution was extruded through a syringe into a homogenous solution of sodium hydroxide- methanol at temperature. Freshly prepared beads were washed thrice with distilled water and resultant beads were allowed to reach with 20 ml of sodium hexameta phosphate (SHMP) 25\% solution for 10 minutes at room temperature. Physically cross linked beads were washed and dipped into $20 \mathrm{ml}$ of glutraldehyde (GA) $(25 \%)$ solution for 10 minutes at $60^{\circ} \mathrm{C}$. Finally, the cross linked beads were washed with distilled water and dried in oven at $40^{\circ} \mathrm{C}$ for $12 \mathrm{hrs}$ [10].

\section{3- Studies of adsorption processes for Ferric (Fe(III)) ions:}

Batch equilibrium isotherm and kinetics studies, were carried out in the same manner. In each type of studies we prepared metal ion solutions containing ferric $(\mathrm{Fe}(\mathrm{III}))$ ions $(0.01 \mathrm{M})$ and transferred them into $(250 \mathrm{ml})$ widemouth propylene test bottles with screw closure caps using a Finn pipette. Each bottle contained a known 
volume $(50 \mathrm{ml})$ of the metal ion solution. A known amount $(0.5 \mathrm{~g})$ of the modified chitosan was added into each bottle. Afterwards, the bottled were shaken continuously (1-120 min). At certain intervals of contact time, the solution sample were withdrawn and filtered and the final concentration of metal ions $\mathrm{Fe}(\mathrm{III})$ was determined in the filtrate by standard EDTA solution $(0.01 \mathrm{M})$. Amount of Ferric $\mathrm{Fe}(\mathrm{III})$ ions adsorbed was then calculated by subtracting its final concentration from initial concentration.

\section{4- Kinetic studies of the adsorption processes for Ferric Fe(III) ions:}

Rate of adsorption process were determined by limited batch technique. Series of adsorption experiments was established at constant temperature. Solutions $(50 \mathrm{ml})$ of Ferric $\mathrm{Fe}(\mathrm{III})$ ions at constant ionic strength $(0.01 \mathrm{M})$ were thermostated at the required temperature $\left(25^{\circ} \mathrm{C}\right)$ in $(250 \mathrm{ml})$ wide-mouth propylene test bottless with screw closure caps using a finn pipette (accurate to \pm 0.03 ).

A weighed amount of the adsorbent $(0.5 \mathrm{gm})$ was added for each solution. The bottles were thoroughly shaken. After appropriate intervals $(30,60,90,120 \mathrm{~min})$, the contents of each bottle separately were filtered and the trivalent metal ion concentration in the liquid phase were determined.

To describe the kinetic process, kinetic data were analyzed based on Lagergren pseudo first-order model [11], and pseudo second order reaction rate model [12]. The mathematical representations of these models are given in Eqs. (1) and (2) as the following:

- Pseudo first-order adsorption kinetic model:

$$
\log \left(q_{e}-q_{t}\right)=\log q_{e}-k_{1} t
$$

Where (qt) is the amount of metal ion adsorbed at time (t). The adsorption rate constant $\left(k_{1}\right)$ (min-1) were calculated from the slope of linear plot of log (qe-qt) versus time $(\mathrm{t})$.

\section{- $\quad$ Pseudo second-order adsorption kinetic model}

$$
\frac{t}{q_{t}}=\frac{1}{k_{2} q_{e}^{2}}+\frac{1}{q_{e}} t
$$

Kinetic model were plotted between (t/qt) against (t).

The rate constant of intraparticle diffusion (kid) at different temperatures were determined using the following equation:

$$
q_{t}=k_{i d} t^{1 / 2}
$$

Where (qt) is the amount adsorbed at time $t,\left(t^{1 / 2}\right)$ is the square root of time.

\section{5- Thermodynamics of the adsorption processes for Ferric Fe(III) ions:}

Thermodynamic parameters for the adsorption processes, including Gibbs free energy change $(\Delta G)$, enthalpy change $(\Delta \mathrm{H})$ and entropy change $(\Delta \mathrm{S})$ were used to decide whether the adsorption process is spontaneous $(\Delta \mathrm{G})$ was calculated from the following equation:

$$
\Delta \mathrm{G}=-\mathrm{RT} \ln K_{\mathrm{D}}
$$

Where $(R)$ is the universal gas constant $\left(8.314 \mathrm{~J} \mathrm{~mol}^{-1} \mathrm{~K}^{-1}\right),(T)$ is the absolute temperature $(K),\left(K_{D}\right)$ is the distribution coefficient of the adsorbate.

The $\left(\mathrm{K}_{\mathrm{D}}\right)$ value was calculated using following equation:

$$
K_{D}=\frac{q_{e}}{C_{e}}
$$

Where $\left(\mathrm{q}_{\mathrm{e}}\right)$ and $\left(\mathrm{C}_{\mathrm{e}}\right)$ are the equilibrium concentration of metal ions on adsorbent $\left(\mathrm{mg} \mathrm{I}^{-1}\right)$ and in the solution $\left(\mathrm{mg} \mathrm{l}^{-1}\right)$, respectively.

Relation between $(\Delta \mathrm{G}),(\Delta \mathrm{H})$ and $(\Delta \mathrm{S})$ can be expressed by the following equation;

$$
\Delta \mathrm{G}=\Delta \mathrm{H}-\mathrm{T} \Delta \mathrm{S}
$$

This equation can be written as;

$$
\ln K_{D}=\frac{\Delta S}{R}-\frac{\Delta H}{R T}
$$


The plot of $\left(\ln K_{D}\right)$ Vs. (1/T) with $(T$ in $K)$ is linear with the slope and intercept values of $(\Delta H$ and $\Delta S)$ respectively.

\section{6-Mechanisms of the adsorption processes for Ferric (Fe(III)) ions:}

It is always important to predict the rate-limiting step in an adsorption process to understand the mechanism associated with the phenomena. For a solid liquid adsorption process, the solute transfer is usually characterized by either external mass transfer or intraparticle diffusion or both. Generally three types of mechanisms are involved in the adsorption process, mentioned as follows [13].

(1) Film diffusion, which involves the movement of adsorbate molecules from the adsorbent.

(2) Particle diffusion, where the adsorbate molecules move in the interior of the adsorbent particles.

(3) Adsorption of the adsorbate molecules on the interior of the porous adsorbent.

\section{7- Effect of temperature on the adsorption processes for Ferric Fe(III) ions:}

To determine the effect of temperature on the adsorption of ferric ( $\mathrm{Fe}(\mathrm{III}))$ ions equilibrium adsorption was performed in several $(250 \mathrm{ml})$ wide-mouth polypropylene bottles with screw closure caps at desired temperature $(298,308$, and $313 \mathrm{~K})$ in absence and in the presence of $(0.1 \mathrm{M}) \mathrm{HCl}$ solution.

Dose of $(0.5 \mathrm{~g})$ of cation exchange resin was firstly weighed accurately and introduced directly into $(250 \mathrm{ml})$ polypropylene bottles. Then, $(50 \mathrm{ml})$ of aqueous solutions containing metal ions with $(0.01 \mathrm{M})$ concentration were added to each bottle and shacked for (120 $\mathrm{min})$ to attain the equilibrium.

The supernatant was removed immediately by filtration. The concentration of the residual aqueous phase was determined by standard EDTA solution $(0.001 \mathrm{M})$. Amount of Ferric $\mathrm{Fe}(\mathrm{III})$ ions adsorbed was then calculated by subtracting its final concentration from initial concentration.

\section{8- Weber and Morris model [14 and 15]:}

The Lagergren first-order and pseudo-second-order models connot identify the diffusion mechanism. For this reason, the kinetic results were then subjected to analyze by the intraparticle diffusion model. According to this model, the plot of uptake (qt) Versus the square root of time (t1/2) should be linear if the intraparticle diffusion is involve in the adsorption process and if these lines pass through the origin then intraparticle diffusion is the rate controlling step. The initial curved portion of the plots seems to be due to boundary layer adsorption and the linear portion to intrapartile diffusion, with the plateau corresponding to equilibrium.

Intraparticle diffusion model is of major concern because it is rate-modeling step in the liquid adsorption systems. During the batch mode of operation, these was a possibility of transport of adsorbate species into the pores of sorbent, which is often the rate controlling step.

\section{9- Metal uptake in the adsorption processes:}

The study of adsorption kinetics describes the solute uptake rate and evidently these rate controls the residence time of adsorbate uptake at the solid-solution interface including the diffusion process. The mechanism of adsorption depends on the physical and chemical characteristics of the adsorbent as well as on the mass transfer process [16]. The amount of metal ion adsorbed per unit mass of the adsorbent $\left(q_{\mathrm{e}}\right)(\mathrm{mg} / \mathrm{g})$ was evaluated by using the following mass balance equation:

$$
q_{e}=\frac{C_{0}-C_{e}}{m} V \text {. }
$$

Where $\left(\mathrm{C}_{0}\right)$ and $\left(\mathrm{C}_{\mathrm{e}}\right)$ are the concentrations $\left(\mathrm{mg} \mathrm{l}^{-1}\right)$ in the solution at time $(\mathrm{t}=0)$ and at equilibrium time $(\mathrm{t}),(\mathrm{V})$ is the volume of solution treated adorbate $(\mathrm{I})$ and $(\mathrm{m})$ is the weight of the adsorbent $(\mathrm{g})$. the percent removal of metal ion was calculated by the following equation:

$$
\text { Removal }(\%)=\frac{C_{0}-C_{e}}{C_{0}} \times 100
$$

\section{RESULTS AND DISCUSSION}

\subsection{Study of adsorption isotherm modeling using Langmiur isotherm:}

Isotherms are the equilibrium relation between the concentration of adsorbate on the solid phase and its concentration in the liquid phase. From the isotherms the maximum adsorption capacity can be obtained. These data provide information on the capacity of the adsorbent or the amount required to remove a unit mass of pollutant under the system conditions. Data has been subjected to different adsorption isotherms. Langmiur, Freundlich, Temkin and Pyzhev and Dubinin-Radushkevich (D-R) models are the most common isotherms describing solid-liquid adsorption system. 
Langmiur isotherm as in Fig (1) and Table (1) is often used to describe adsorption of solute from liquid solutions and this model assumes monolayer adsorption onto a homogeneous surface with finite number of identical sites and expressed by the following (eq. (1)).

$$
\mathrm{q}_{\mathrm{e}}=\frac{\mathrm{Q}_{\circ} \mathrm{kL}_{\mathrm{L}} \mathrm{C}_{\mathrm{e}}}{1+\mathrm{k}_{\mathrm{L}} \mathrm{C}_{\mathrm{e}}}
$$

Table (1): Adsorption of isotherm parameters for Fe(III) by modified chitosan:

\begin{tabular}{|c|c|c|c|c|c|c|}
\hline \multicolumn{3}{|c|}{ Langmiur parameters } & \multicolumn{3}{c|}{ Freundlich parameters } \\
\hline $\begin{array}{c}\mathrm{Q}_{\circ} \\
(\mathrm{mg} / \mathrm{g})\end{array}$ & $\begin{array}{c}\mathrm{b} \\
(\mathrm{L} / \mathrm{mg})\end{array}$ & $\mathrm{R}_{\mathrm{L}}$ & $\mathrm{R}^{2}$ & $\mathrm{n}$ & $\begin{array}{c}\mathrm{k}_{\mathrm{f}} \\
(\mathrm{mg} / \mathrm{g})\end{array}$ & $\mathrm{R}^{2}$ \\
\hline 20.6611 & -0.1072 & -0.0170 & 0.9999 & -6.5445 & 46.2168 & 0.9977 \\
\hline
\end{tabular}

\begin{tabular}{|l|l|l|}
\hline & Fe(III) & y $=0.0484 \times-0.4516$ \\
$R^{2}=0.9999$ \\
5.0
\end{tabular}

(Fig.1) Langmiur plot for removal of Fe(III) by modified chitosan

Characteristic constants of Langmiur equation, $Q_{0}$ the theortical maximum adsorption capacity and $k_{L}$ related to affinity of the binding sites, $Q_{0}$ and $k_{L}$ Langmiur isotherm constants can be determined from the linearized of $\mathrm{Eq}(1)$ as inq(2):

$$
\frac{C_{e}}{q_{e}}=\frac{1}{\mathrm{bQo}}+\frac{C_{e}}{\mathrm{Qo}}
$$

The slope and intercept of the linear plot (Fig.1) of $\left(C_{e} / q_{e}\right)$ Verses $\left(C_{e}\right)$ give the values of $Q_{0}$ and $k_{L}$ respectively. In order to know the feasibity of the isotherm, the essential features of Langmiur model can be expressed in the terms of separation factor or equilibrium parameter $R_{L}$, which was defined by $E q(3)$ :

$$
\mathrm{R}_{\mathrm{L}}=\frac{1}{1+b C o}
$$

The values of $R_{L}$ indicate the shapes of isotherms to be either unfavorable $\left(R_{L}>1\right)$, linear $\left(R_{L}=1\right)$, favorable $(0<$ $\left.R_{L}<1\right)$ or irreversible $\left(R_{L}=0\right)$ [16]. The $R_{L}$ values for $F e(I I I)$ were calculated and indicated that adsorption is even favorable for the higher metal ion concentration that have been investigated. The data of $R_{L}$ values the adsorbent is suitable adsorbent (modified chitosan) for the adsorption of $\mathrm{Fe}(\mathrm{III})$ ions from aqueous solutions.

\subsection{Study the adsorption isotherm modeling using Fruendlich isotherm:}

The freundlich mode (Fig. 2) is expressed as follows (Eq. 4):

$$
\mathrm{q}_{\mathrm{e}}=\mathrm{k}_{\mathrm{f}} \mathrm{C}_{\mathrm{e}} 1 / \mathrm{n}-
$$

The linearized form of Freundlich equation are given by (Eq. 5):

$$
\ln \mathrm{q}_{\mathrm{e}}=\ln \mathrm{k}_{\mathrm{f}}+(1 / \mathrm{n}) \ln \mathrm{C}_{\mathrm{e}}
$$

Where $k_{f}$ and $1 / n$ are characteristic constants representing the adsorption capacity and adsorption intensity of the system respectively. The linear plot between ( $\ln \mathrm{q}_{\mathrm{e}}$ ) verses $\left(\ln \mathrm{C}_{\mathrm{e}}\right.$ ) gives a slope which is equal to the value of $(1 / n)$ and intercept is $\left(\ln _{\mathrm{f}}\right)$. The magnitude of $0<n<1$ indicates the favorability of process of adsorption.

The adsorption parameters obtained from both the models were given in Table (1). The experimental data were fitted well with Langmiur isotherm suggesting that the $\mathrm{Fe}(\mathrm{III})$ adsorbed from monolayer coverage on the adsorbent surface. To lesser extent, the equilibrium data were also well described with the Freundlich model probably due to the real heterogeneous nature of the surface sites involved in the process of adsorption (Fig. 2) and Table (2). 


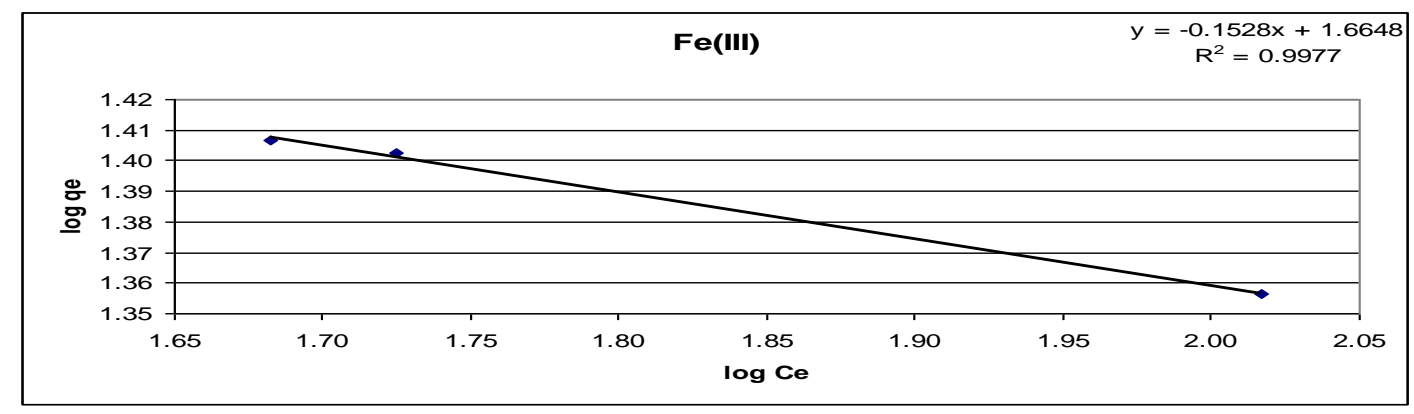

(Fig.2) Freundlich plot for removal of Fe(III) by modified chitosan

The correlation co-efficient $\left(R^{2}\right)$ value indicates that both the models can be used to describe the adsorption process. Our data of $(n)$ values between zero and one indicating that the adsorption of $\mathrm{Fe}(\mathrm{III})$ onto the adsorbent modified chitosan was favorable at the studied conditions. This can be attributed to the fact that, when the $\mathrm{Fe}(\mathrm{III})$ ions present in the solution, may diffuses to the surface sites slowly or rapidly, however, diffusion might be retarded when the Fe(III) ions are hydrated. It is possible that with fewer weakly bonded water molecules they tend to move faster to the potential adsorption sites, when compared to the cations with higher hydrated ionic radii [18].

On the other hand, the equilibrium data were analyzed using Freundlich isotherm model and $\left(R^{2}\right)$ values were estimaled. The value of $(n)$ generally indicates that the adsorption capacity is only slightly suppressed at lower equilibrium concentrations. This isotherm does not predict any saturation of the adsorbent by Fe(III) ions; this infinite surface coverage is expected to occur indicating multilayer adsorption on the surface. It can be concluded that the Langmuir isotherm was more suitable than Freundlich one as in most cases the correlation co-efficient was higher as seen in Table(1) thus indicating the applicability of monolayer coverage of the $\mathrm{Fe}$ (III) ions on the surface of adsorbent. This can be explained by the fact that the adsorbent have a high surface area for Fe(III) ions adsorption. Therefore only monolayer adsorption occurred on their surface.

\subsection{Study the adsoption isotherm modeling using Temkin and Pyzhev isotherm:}

The model assumes the following facts: (i) the heat of the adsorption of all molecules of the layer decreases linearly with coverage due to adsorbent-adsorbate interactions, and then (ii) the adsorption is characterized by a uniform distribution of binding energies, up to a maximum binding energy. The derivation of the Temkn in isotherm assumes that the fall in the of adsorption is linear rather than logarithmic, as implied in the Freundlich equation.

The Temkin ana Pyzhev isotherm has commonly been applied in the following (Eq. 6).

$$
\begin{aligned}
& \mathrm{q}_{\mathrm{e}}=(\mathrm{RT} / \mathrm{b}) \ln \left(\mathrm{AC}_{\mathrm{e}}\right) \text {-- } \\
& \mathrm{q}_{\mathrm{e}}=\left(\mathrm{RT} / \mathrm{b}_{\mathrm{T}}\right) \ln \mathrm{A}_{\mathrm{T}}+\left(\mathrm{RT} / \mathrm{b}_{\mathrm{T}}\right) \ln \mathrm{C}_{\mathrm{e}} \\
& \mathrm{B}_{\mathrm{T}}=\mathrm{RT} / \mathrm{b}_{\mathrm{T}}
\end{aligned}
$$

Where $\left(A_{T}\right)(L / g)$ and $\left(b_{T}\right)(\mathrm{J} / \mathrm{mol})$ are Temkin isotherm constants, $(R)$ is the gas constant $(8.314 \mathrm{~J} / \mathrm{mol})(\mathrm{T})$ is he absolute temperature.

The Temkin and Pyzhev isotherm for the Fe(III) ions as shown in Fig.(3)

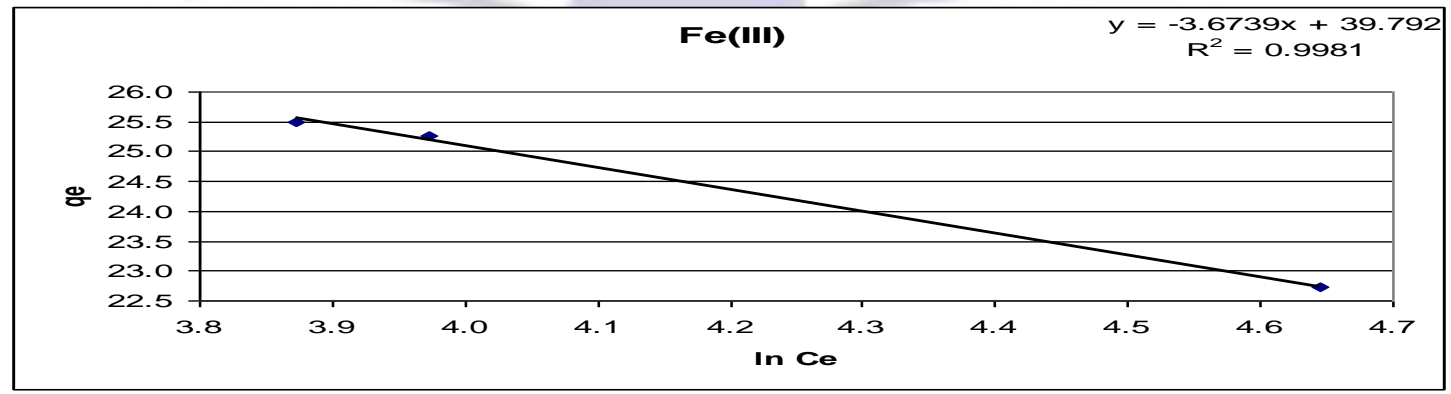

(Fig.3) Temkin plot for removal of Fe(III) by modified chitosan

The related parameters are given in Table (2). $\left(b_{T}\right)$ related to heat of adsorption. Values higher than 8 indicates strong interaction between $\mathrm{Fe}(\mathrm{III})$ and adsorbent. However, higher value indicates presence of relatively stronger cohesive forces in between the adsorbent and Fe(III). 
Although the Frenudlich isotherm provides the information about the surface heterogeneity and the exponential distribution of the active sites and their energies, it does not predict any saturation of the surface of the adsorbent by the adsorbate. Hence, infinite surface coverage could be predicted mathematically. In contrast, Dubinin-Radushkevich (D-R) isotherm the heterogeneity of energies closes to the adsorbent surface. If a very small subregion of adsorption surface is chosen and assumed to be approximately by the Langmuir isotherm (Fig. 4).

The Dubinin-Radushkevich (D-R) isotherm [19] was also employed to find out the adsorption mechanism based on the potential theory assuming a heterogeneous surface. Dubinin-Radushkevich isotherm is expressed as follows (Eq.9):

$$
q_{e}=X_{m} e^{-\beta \varepsilon 2}
$$

The liner form was (Eq. 10):

$$
\ln q_{e}=\ln X_{m}-\beta \varepsilon^{2}
$$

Where $\left(X_{m}\right)$ is the Dubinin-Radushkevich monolayer capacity $(\mathrm{mg} / \mathrm{g}),(\beta)$ is a constant related to adsorption energy, and $(\varepsilon)$ is the polanyi potential [20] which is related to the equilibrium concentration as follows in (Eq. 11):

$$
\varepsilon=R T \ln \left(1+\left(1 / C_{e}\right)\right)
$$

Where $(R)$ is the gas constant $(8.314 \mathrm{~J} / \mathrm{mol} \mathrm{K})$ and $(T)$ is absolute temperature

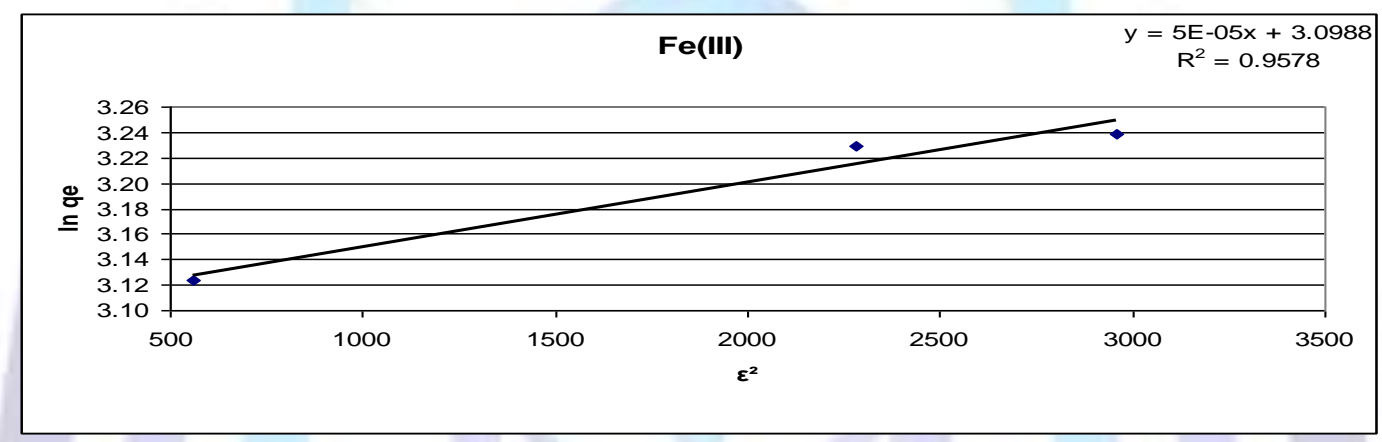

Fig.4) D-R plot for removal of Fe(III) by modified chitosan

A plot of (In qe) Vs $\left(\varepsilon^{2}\right)$ as in (Fig. 4) gave a straight line of slope, $(\beta)$ and intercept, $(\mathrm{Xm})$ of different systems were evaluated. The difference in the free energy between the adsorbed phase and the saturated liquid adsorbate is referred to as the potential, a term first advanced by Polanyi [20].

Thus the adsorption space in the vicinity of the solid surface may be characterized by a series of equipotential surfaces with a given adsorption potential. The adsorption potential is independent of temperature but varies according to the nature of the adsorbent and adsorbate. In the present study Dubinin-Radushkevich isotherm constants, monolayer capacity $\left(X_{m}\right)$ and adsorption energy $(\beta)$ are tabulated in Table (2).

The magnitude of $(\beta)$ is used to determine the type of adsorption mechanism. When one mole of $\mathrm{Fe}(\mathrm{III})$ ions is transferred the adsorbent surface, its value is higher than $8.0 \mathrm{KJ} / \mathrm{mol}$ which indicates chemical adsorption, the calculated values of $(E)$ for the present study is higher than $8.0 \mathrm{KJ} / \mathrm{mol}$ for the adsorption of Fe(III), which suggest that adsorption process onto the surface of the adsorbent modified chitosan is following chemical

\begin{tabular}{|c|c|c|c|c|c|c|}
\hline & \multicolumn{2}{|c|}{ Temkin parameters } & \multicolumn{2}{|c|}{ D-R parameters } & & \\
\hline$A_{T}$ & $\mathrm{~B}_{\mathrm{T}}$ & $\mathrm{R}^{2}$ & B & $Q_{\circ}$ & $E$ & $\mathrm{R}^{2}$ \\
\hline$(\mathrm{L} / \mathrm{g})$ & $(\mathrm{J} / \mathrm{mol})$ & & & $(\mathrm{mg} / \mathrm{g})$ & $(\mathrm{KJ} / \mathrm{mol})$ & \\
\hline $1.9777 \times 10^{-5}$ & -3.6739 & 0.9981 & $5.0000 \times 10-5$ & 22.1713 & 100.0000 & 0.9578 \\
\hline
\end{tabular}
adsorption type.

Table (2): Adsorption of isotherm parameters for Fe(III) by modified chitosan

\subsection{Study the adsorption kinetics modeling:}

The study of adsorption dynamics describes the solute uptake rate and evidently this rate controls the residence time of adsorbate uptake at the solid/solution interface. The data of the kinetics of $\mathrm{Fe}(\mathrm{III})$ adsorbed from aqueous solution onto modified chitosan as illustrated in Fig. (5-10) were analyzed using pseudo first order, pseudo second order imtraparticle diffusion kinetic models, respectively. The conformity between experimental data and each model predicted values was expressed by the correlation coefficient $\left(R^{2}\right)$. A 
relatively high $\left(\mathrm{R}^{2}\right)$ values indicated that the model successfully describes the kinetics of $\mathrm{Fe}(\mathrm{III})$ ions adsorption removal.

The adsorption kinetics of $\mathrm{Fe}$ (III) ions from liquid phase to solid is considered as a reversible reaction with an equilibrium state being established between two phases. A simple pseudo first-order model was therefore used to correlate the rate of reaction and expressed as follows (Eq. 12):

$$
\mathrm{dq}_{\mathrm{t}} / \mathrm{dt}=\mathrm{k}_{1}\left(\mathrm{q}_{\mathrm{e}}-\mathrm{q}_{\mathrm{t}}\right)
$$

Where $\left(q_{e}\right)$ and $\left(q_{t}\right)(\mathrm{mg} / \mathrm{g})$ are concentration of $F e(I I I)$ ions in the adsorbent at equilibrium and at time (t), respectively integration and applying boundary conditions $(\mathrm{t}=0$ to $\mathrm{t}=\mathrm{t})$ and $\left(\mathrm{q}_{\mathrm{t}}=0\right.$ to $\left.\mathrm{q}_{\mathrm{t}}=\mathrm{q}_{\mathrm{t}}\right)$, the integrated from of (Eq. 12) becomes (Eq. 13):

$$
\log \left(q_{e}-q_{t}\right)=\log q_{e}-\left(k_{1} / 2.303\right) t-
$$

Plots for (Eq. 13) were made for the Fe(III) ions adsorption at different studied temperature, and shown in Fig. (5, 6 and 7$)$. Approximately linear fits were observed for the $\mathrm{Fe}(\mathrm{III})$ ions, over the entire range of shaking time explored and at all temperatures with low correlation coefficient as in Table (3), indicating that the pseudo first order kinetic model is not valid for the present systems.

A pseudo second-order rate model is also used to describe the kinetics of the adsorption of Fe(III) ion adsorbent materials. The differential equation for chemisorptions kinetic rate reaction is expressed as (Eq. 14):

$$
\mathrm{dq}_{\mathrm{t}} / \mathrm{dt}=\mathrm{k}_{2}\left(\mathrm{q}_{\mathrm{e}}-\mathrm{q}_{\mathrm{t}}\right)^{2}
$$

Where $k_{2}$ is the rate constant of pseudo second-order equation, for the boundary co-nditions $(t=0$ to $t=t)$ and $\left(q_{t}=0\right.$ to $\left.q_{t}=q_{t}\right)$, the integrated from of (Eq. 14) becomes (Eq. 15):

$$
1 /\left(q_{e}-q_{t}\right)=1 / q_{e} t
$$

Eq. (15) can be rearranged to obtain a linear form equation as Eq. (16):

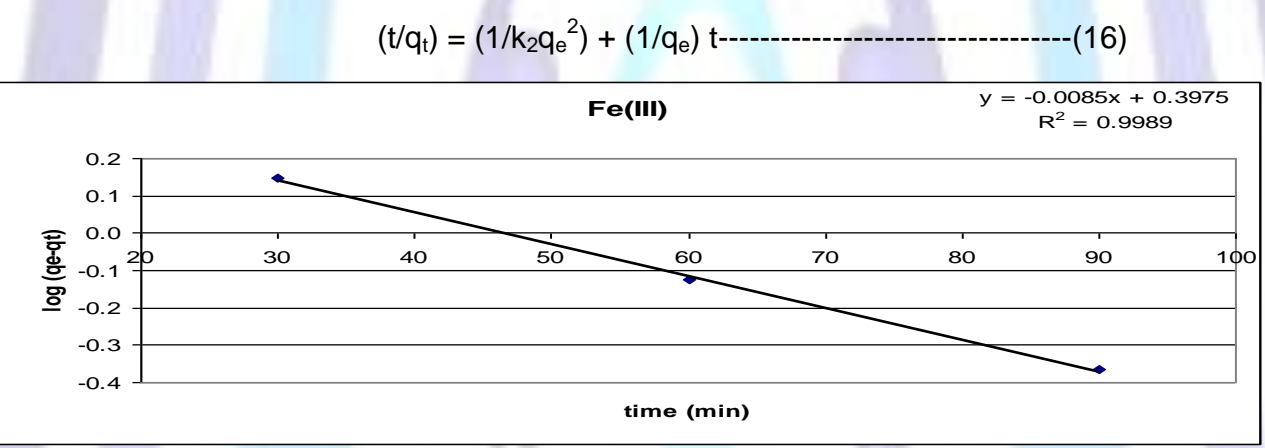

(Fig.5) Pseudo first order plot for removal of Fe(III) by modified chitosan at $25^{\circ} \mathrm{C}$

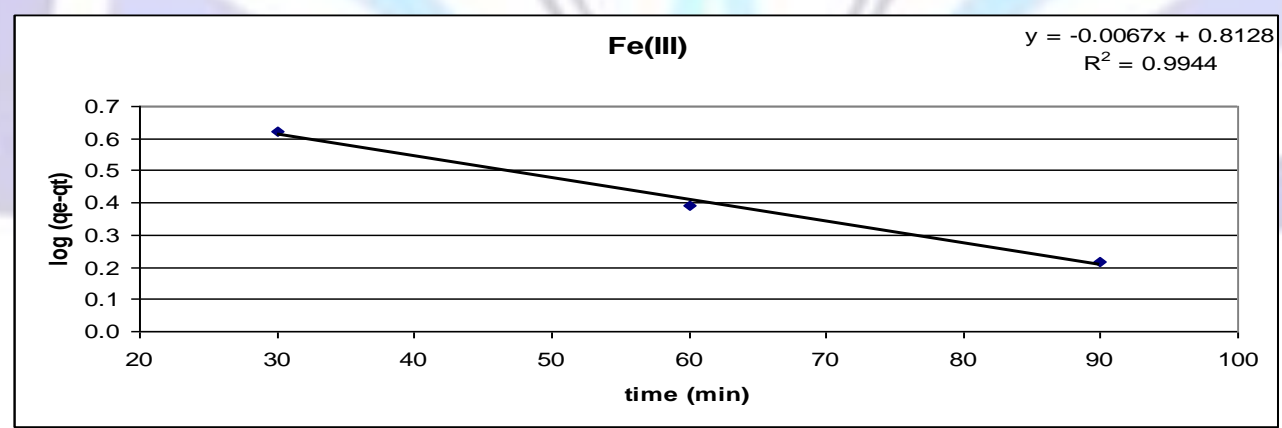

(Fig.6) Pseudo first order plot for removal of Fe(III) by modified chitosan at $35^{\circ} \mathrm{C}$

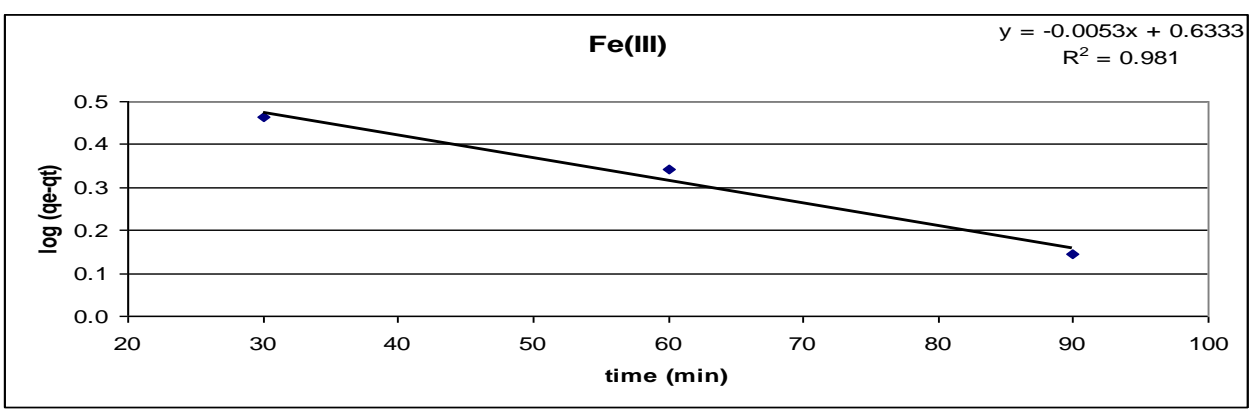


(Fig.7) Pseudo first order plot for removal of $\mathrm{Fe}(\mathrm{III})$ by modified chitosan at $45^{\circ} \mathrm{C}$

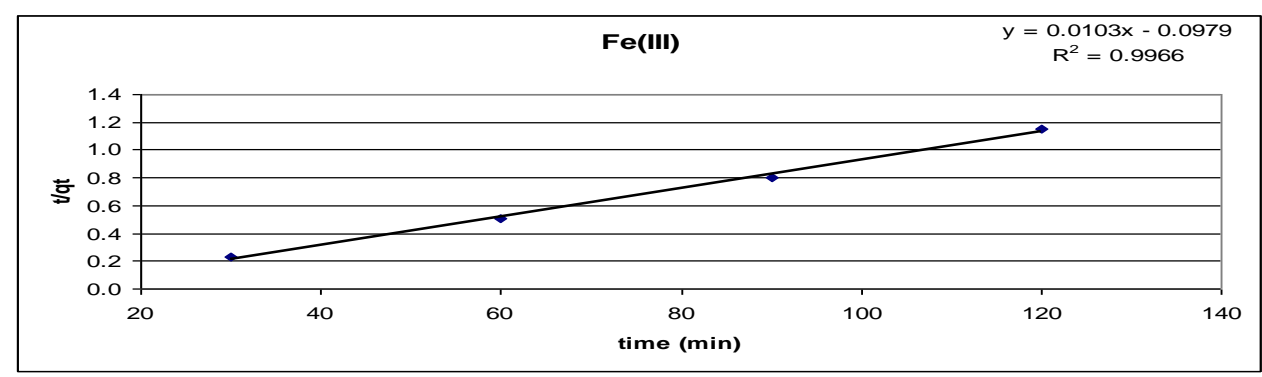

(Fig.8) Pseudo second order plot for removal of Fe(III) by modified chitosan at $25^{\circ} \mathrm{C}$

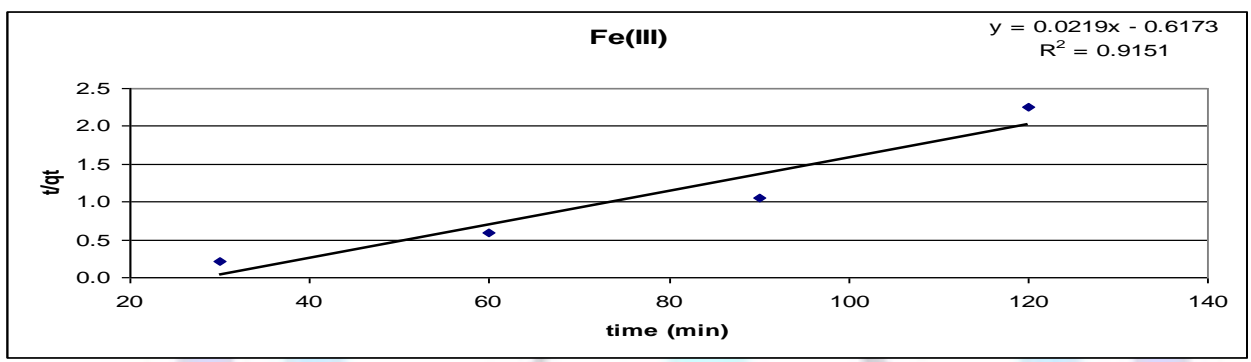

(Fig.9) Pseudo second order plot for removal of $\mathrm{Fe}$ (III) by modified chitosan at $35^{\circ} \mathrm{C}$

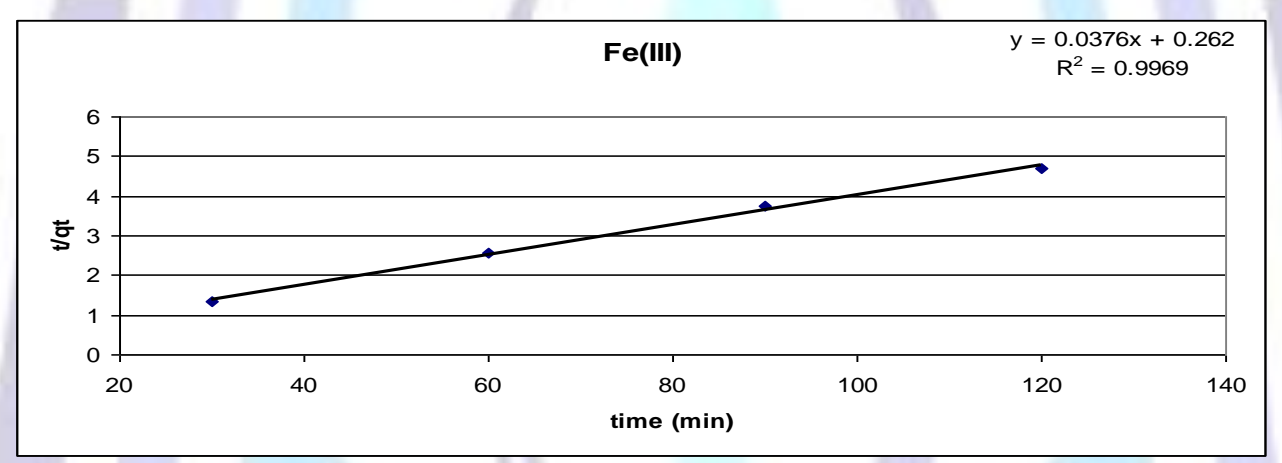

(Fig.10) Pseudo second order plot for removal of $\mathrm{Fe}$ (III) by modified chitosan at $45^{\circ} \mathrm{C}$

The kinetic plots of (t/qt) versus (t) for Fe(III) ions adsorption at different temperature are present in $(8,9$ and 10). The relationships are linear, and the values of correlation coefficient $\left(R^{2}\right)$, suggest a strong relationship between the parameters and also explain that the process of adsorption of $\mathrm{Fe}(\mathrm{III})$ ions follows pseudo second order kinetic model.

Table (3): Kinetic parameters for removal of Fe(III) ions by modified chitosan:

\begin{tabular}{|cccccccc|}
\hline \multicolumn{3}{|c|}{ Pseudo first-order } & \multicolumn{7}{c|}{ Pseudo second-order } \\
\hline $\begin{array}{c}\mathrm{q}_{\mathrm{e}, 1} \\
(\mathrm{mg} / \mathrm{g})\end{array}$ & $\begin{array}{c}\mathrm{K}_{1} \\
\left(\mathrm{~min}^{-1}\right)\end{array}$ & $\mathrm{R}^{2}$ & $\begin{array}{c}\mathrm{q}_{\mathrm{e}, 2} \\
(\mathrm{mg} / \mathrm{g})\end{array}$ & $\begin{array}{c}\mathrm{K}_{2} \\
(\mathrm{~g} / \mathrm{mg} \mathrm{min})\end{array}$ & $\begin{array}{c}\mathrm{H} \\
(\mathrm{mg} / \mathrm{g} \mathrm{min})\end{array}$ & $\mathrm{R}^{2}$ & $\mathrm{~T}$ \\
\hline 2.4975 & 0.0196 & 0.9989 & 26.5957 & 0.0054 & 3.8168 & 0.9969 & 298 \\
4.2983 & 0.0122 & 0.9810 & 26.3158 & 0.0051 & 3.5026 & 0.9952 & 308 \\
6.4983 & 0.0154 & 0.9944 & 22.9358 & 0.0232 & 12.1803 & 0.9995 & 318 \\
\hline
\end{tabular}

From the results, it can be shown that the value of the rate constant $\left(k_{2}\right)$ were increased with increase in temperature the correlation coefficient $\left(R^{2}\right)$ has an extremely high value, and theoretical $\left(q_{e}\right)$ values agree with experimental ones. These results suggest that the pseudo second-order adsorption mechanism is predominant and that the overall rate constant of each $\mathrm{Fe}(\mathrm{III})$ ion appears to be controlled by the chemisorptions process. 


\subsection{Study the intra-particle diffusion model (Weber-Marries) model:}

The overall reaction kinetics for the adsorption of some toxic metal ions as: Fe(III) is a pseudo Frst-order process, however, this could not high light on the rate-limiting step. The rate limiting step (slowest step of the reaction) may be either the boundary layer (film) on intraparticle (pore) diffusion of solute on the solid surface from the bulk of the solution in the batch process. The probability of the intraparticle diffusion was explored by using the Marris's and Weber's pore-diffusion model.

At the present time Weber and Morris's and pore-diffusion is the most widely used models for studying the mechanism of adsorption. On the other hand, Weber and Morris's pore-diffusion model assumes that:

(i) The external resistance mass transfer is only significant for a very short period the beginning of diffusion.

(ii)The direction of diffusion is radial and the concentration.

(iii) The pore diffusivity is constant and does not change with time, the pore diffusion parameter, $\mathrm{kid}((\mathrm{mg} / \mathrm{g}$ $\min ^{0.5}$ ) is expressed as (Eq. 17):

$$
\mathrm{qt}=\mathrm{k}_{\mathrm{id}} \mathrm{t}^{0.5}+\mathrm{C}
$$

Where $\left(q_{t}\right)$ is the amount adsorbed $(\mathrm{mg} / \mathrm{g})$ at time $(\mathrm{t})$.

The $\left(k_{i d}\right)$ values were obtained as in table (4) from the slope of the linear portions of the curve of different initial concentration of the Fe(III) ions in aqueous solution and shown in Fig (11-13). It can be seen that the plots possess multilinear portions; it indicates that the two or more steps influence the adsorption process. It was found that straight lines relate the points, the sharp first linear portion is due to the film diffusion and the second linear portion is due to the pore diffusion. Non-linearity of the plots had indicated the multi stage adsorption of toxic metal as $\mathrm{Fe}$ (III) by the adsorbent. The extrapolation of the first linear portion gives the intercept equal to the boundary layer thickness or film thickness. The values of intercept give an idea about the boundary layer thickness such as the layer the intercept, the greater the boundary layer effect.

Table (4): The intra-particle diffusion model (Weber-Marries) model for removal ofFe(III) by modified chitosan

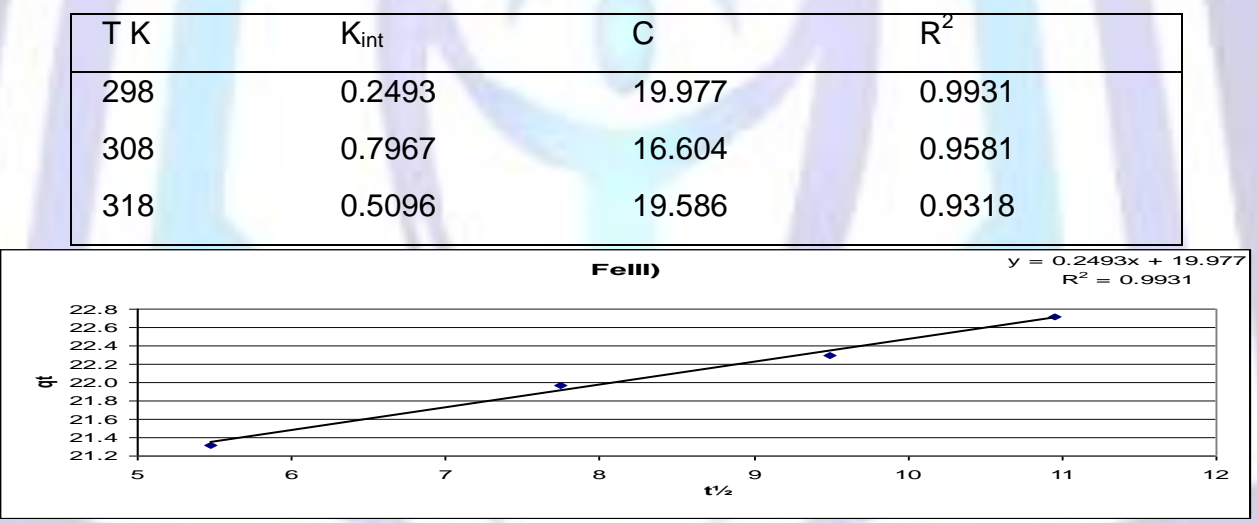

(Fig. 11) The intra-particle diffusion model (Weber-Marries) model for removal of Fe(III) by modified chitosan at $25^{\circ} \mathrm{C}$

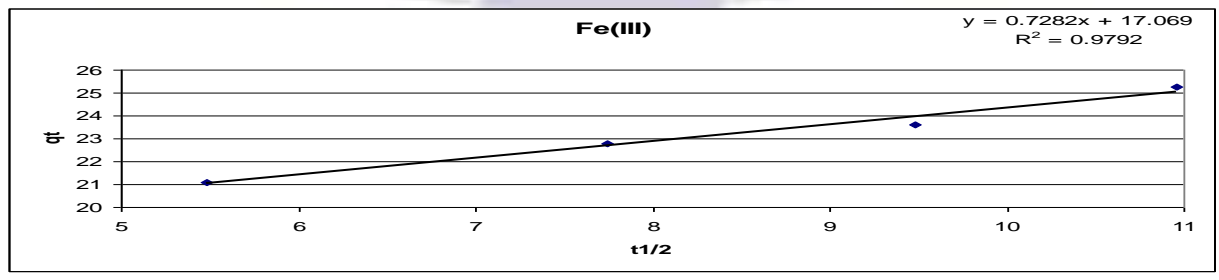

(Fig. 12) The intra-particle diffusion model (Weber-Marries) model for removal of Fe(III) by modified chitosan at $35^{\circ} \mathrm{C}$ 


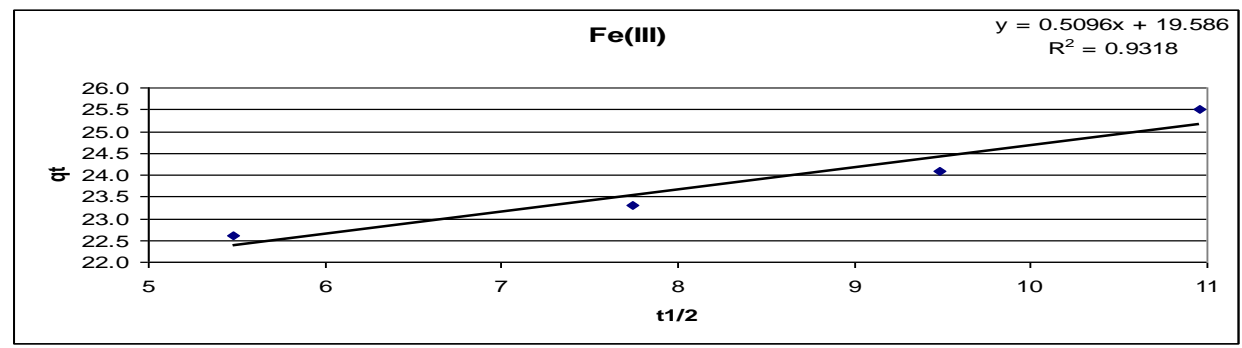

(Fig. 13) The intra-particle diffusion model (Weber-Marries) model for removal of $\mathrm{Fe}$ (III) by modified chitosan at $45^{\circ} \mathrm{C}$

\subsection{Study the effect of temperature and calculation of activation energy $\left(E_{a}\right)$ :}

The thermodynamic assumptions of the best fitting isotherm provide insight into the surface properties and the mechanism of adsorption. The experimental results obtained as in Fig. (14) from a series of contact time studies for $\mathrm{Fe}(\mathrm{III})$ ion adsorption with an initial concentration of $(10 \mathrm{~m} \mathrm{~mol} / \mathrm{L})$ in aqueous solution in which temperature was varied from $\left(25\right.$ to $\left.45^{\circ} \mathrm{C}\right)$.

The adsorption of $\mathrm{Fe}(\mathrm{III})$ ions has been found to increase with an increase in temperature from $\left(25\right.$ to $\left.45^{\circ} \mathrm{C}\right)$. The increase in adsorption capacity of the adsorbent with temperature indicates an endothermic process as in table (5).

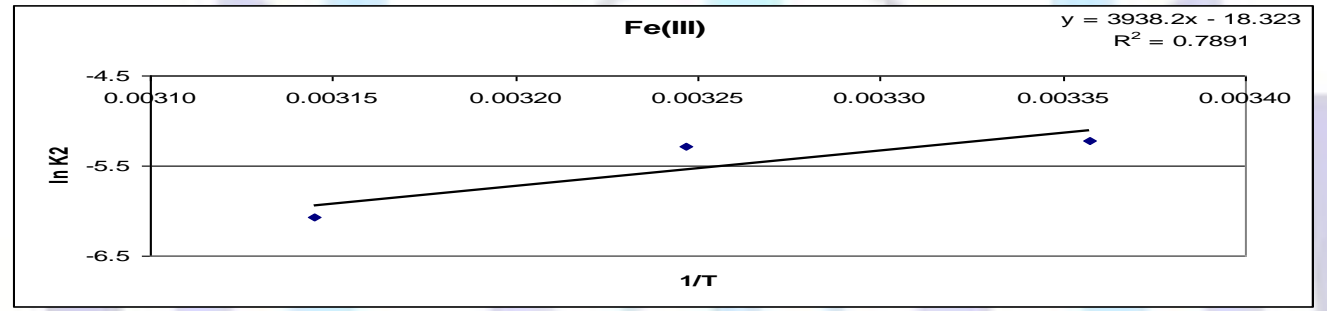

Fig.(14) Arrhenius equation for removal of Fe(III) by modified chitosan

The increase in adsorption with temperature my be attributing to either change in pore size of the adsorbent causing inter-particle diffusion within the pores or to enhancement in the chemical affinity of the Fe(III) ions to the surface of adsorbent leading to some kind of chemical interaction to take during adsorption process which results into increase in adsorption capacity. At higher temperature, the possibility of diffusion of solute within the pores of adsorbent may not ruled out as reposted by earilier warkers [22].

Since diffusion is an endothermic process, greater adsorption will be observed at higher temperature. Thus the diffusion rate of ions in the external mass transport process increases with temperature.

Table (5) Thermodynamic parameters for removal of Fe(III) by modified chitosan

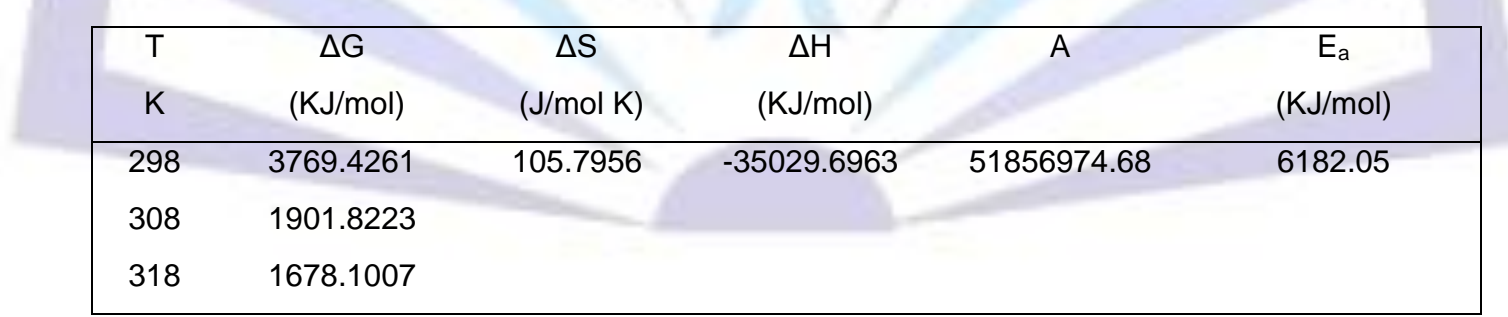

The above results were further substantiated by the various thermodynamic parameters. Enthalpy change $(\Delta \mathrm{H})$, Entropy change $(\Delta S)$, Gibbs free energy change $(\Delta G)$ and Activation energy $\left(E_{a}\right)$ evaluated for adsorption.

The effect of temperature on adsorption is further confirmed by the vant Holf plots as Fig. (14) based on the equations $(18,19,20$ and 21$)$ [23]:

$$
\begin{aligned}
& \mathrm{k}_{\mathrm{D}}=\mathrm{q}_{\mathrm{e}} / \mathrm{C}_{\mathrm{e}}- \\
& \Delta \mathrm{G}=-\mathrm{RT} \ln \mathrm{k}_{\mathrm{D}}- \\
& \Delta \mathrm{G}=\Delta \mathrm{H}-\mathrm{T} \Delta \mathrm{S} \text { - } \mathrm{k}_{\mathrm{D}}=(\Delta \mathrm{S} / \mathrm{R})-(\Delta \mathrm{H} / \mathrm{RT})
\end{aligned}
$$

Where $(T)$ is absolute temperature in Kevin $(K), R$ is gas constant $(8.314 \mathrm{~J} / \mathrm{mol} \mathrm{K})$ and $\mathrm{k}_{\mathrm{D}}$ is the distribution coefficient $(\mathrm{ml} / \mathrm{g})$. The thermodynamic parameters namely enthalpy change $(\Delta \mathrm{H})$ and entropy change $(\Delta \mathrm{S})$ can be calculated from the slope and intercept of straight line plotted by (In $\mathrm{k}_{\mathrm{D}}$ ) versus $(1 / \mathrm{T})$ as in Fig. (14) 
respectively. The Gibbs free energy change $(\Delta G)$ was dete-rmined. The obtained thermodynamic parameters $\left(\Delta \mathrm{H}, \Delta \mathrm{S}, \Delta \mathrm{G}\right.$ and $\left.\mathrm{E}_{\mathrm{a}}\right)$ were listed in Table (5).

By adsorption abundant $\mathrm{Fe}(\mathrm{III})$ ions onto the surface of the adsorbent, the number of $\mathrm{H}+$ ions attached to activate sites of the adsorbent decreased. Therefore the positive value of $\Delta S$ suggested some structure change in the adsorbent and adsorbate. In fact, the positive value of enthalpy $(\Delta \mathrm{H})$ further confirmed the endothermic nature of the processes, so increasing temperature supplied with a more favorable adsorption of $\mathrm{Fe}$ (III) ions onto the adsorbent. The negative Gibbs free energy $(\Delta G)$ value for the metal adsorption process on the adsorbent indicates the spontaneous nature of the adsorption process.

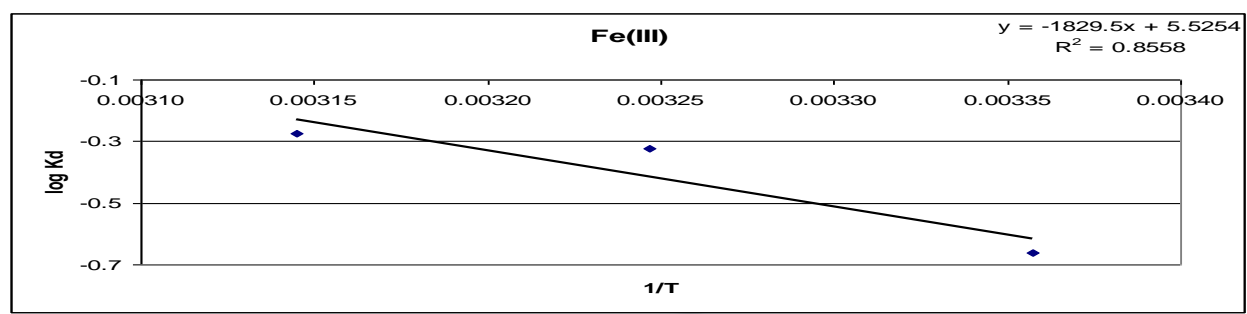

(Fig. 15) The effect of temperature on removal of Fe(III) by modified chitosan by The Vant Holf polts

Generally, The values of the change in enthalpy $(\Delta \mathrm{H})$ indicated that adsorption process of $\mathrm{Fe}(\mathrm{III})$ is physical in nature [24].

The activation energy $\left(E_{a}\right)$ was calculated by the linearized Arrhenius equation (eq. 22):

$$
\ln (k)=\ln (A)-\left(E_{a} / R T\right)
$$

where $\left(E_{a}\right)$ is the activation energy of adsorption $\left(\mathrm{KJmol}^{-1}\right),(\mathrm{k})$ is the rate constant which control the process, $(A)$ is Arrhenius constant, $(R)$ is the ideal gas constant $(8.314 \mathrm{~J} / \mathrm{mol} \mathrm{K})$ and $(T)$ is the absolute temperature $(K)$.

From the pseudo second-order kinetic studies, $k_{2}$ is the rate constant which control the process, i.e (k) In this study, activation energy $\left(E_{a}\right)$ value of different systems under study $(\mathrm{KJ} / \mathrm{mol})$ was obtained from the plot of (In $\mathrm{k}_{2}$ ) versus $(1 / \mathrm{T})$ as in Fig.(14).

In physical adsorption, the activation energy $\left(E_{a}\right)$ usually more than $8.0 \mathrm{KJmol}^{-1}$, since the forces involved in chemical adsorption is high.

Chemical adsorption involves forces much stronger than in physical adsorption and the activation energy $\left(E_{a}\right)$ is between (8.4) and (83.7) $\mathrm{KJmol}^{-1}$ [22] noted that chemical adsorption includes activated and non activated forms. Activated chemical adsorption means that the rate varies with temperature according to finite activation energy $\left(E_{a}\right)$ (between 8.4 and $83.7 \mathrm{KJmol}^{-1}$ ) in the Arrhenius equation, but the activation energy $\left(E_{a}\right)$ for non activation chemical adsorption is near zero.

The results shows that the process is one of activated chemical adsorption and the positive value of the activation energy $\left(E_{a}\right)$ suggested that the rise in the solution temperature favors the $\mathrm{Fe}(\mathrm{III})$ ions adsorption onto the modified chitosan

\section{REFERENCES}

[1] Nasef, M. M., and Yaha, A. h., 2009. Adsorption of some heavy metal ions from aqueous solutions on Nafion 117 membrane, Desalination, 249(2), 677-681.

[2] Wolthoom, A., Temminghoff, E. J., Weng, L., and Riemsdijk, W. H., 2004. Colloid formation in groundwater: effect of phosphate, manganese, silicate and dissolved organic matter on the dynamic heterogeneous oxidation of ferrous iron, Applied Geochemi., 19(4) 611-622.

[3] Reiad, N. A., Abdelsalam, O. E., Abadir, E. F., and Harraz, F. A., 2012 Adsorptive removal of iron and manganese ions from aqueous solutions with microporous chitosan/polyethylene glycol blend membrane, Journal of Environmental Sciences, 24(8), 1425-1432.

[4] Karunakaran, K., and Thamilarasu, P., 2010. Removal of Fe(III) from aqueous solutions using rcinus communis seed shell and polypyrole coated ricinus communis seed shell activated carbons, International Journal of ChemTech Research vol. 2, No. 1, 26-35.

[5] Mahmoud, M. E., Osman, M. M., Hafez, O. F., and Elmelegy, E., 2010. Removal and preconcentration of lead (II), copper (II), chromium (III) and iron (III) from wastewaters by surface developed alumina adsorbents with immobilized 1-nitroso-2-naphthol, J. of Hazardous Materials, 173, 349-357.

[6] Quinteleas, C., Rocha, Z., Silva, B., Fonseca, B., Figueiredo, H., and Tavares, T., 2009. Removal of Cd(II), Cr(VI), $\mathrm{Fe}(\mathrm{III})$ and $\mathrm{Ni}$ (II) from aqueous solutions by an E. coli biofilm supported on kaolin, Chem. Eng. J. 149,319-324.

[7] Camel, V., 2003. Solid ph. extr. of trace elements, Spectrochim- Acta p. B 58;1177-1233. 
[8] Jal, P. K., Patel, S., and Mishra, B. K., 2004. Chemical modif. of silica surface by immobilization of functional groups for extractive conc. of metal ions, Talanta 62, 1005-1028.

[9] Wassel, M. A., Swlem, A. A., Shama, S. A., Hamoda, A. A., and Desouky, A. M., 2013. Water salinity total, temporary and permanent of the pleistoceme Aqifr samples in El-Sadat area. Al-Azhar Bull. Sci; vol. 24. No. 1 (June): pp. 33-48.

[10] Kumari, K., and Rani, U., 2011. Controlled Release of Metformin hydrochloride through crosslinked blends of chitosan-starch, Adv. Appl. Sci. Res., 2(2), 48-54.

[11] Najafi, M., Yousefi, Y., and Rafati, A. A., 2012. Synthesis, characterization and adsorption studies of several heavy metal ions on amino-functionalized silica nano hollow sphere and silica gel, Sep. and Pur. Technol., 85, $193-205$.

[12] Huang, J., Cao, Y., Liu, Z., Deng, Z., and Tang, F., 2012. Efficient removal of heavy metal ions from water system by titanate nanoflowers, J. Chem. Eng. 180, 75-80.

[13] Szlachta, M., Gerda V., and Chubar, N.,2012. Adsorption of arsenite and selenite using an inorg ion exchanger based on Fe-Mn hydrous oxide, J. of col. and interf. Sci. 365, 213-221.

[14] Niboua, D., Mekatela, H., Amokranea, S., Barkatb, M., and Traric, M., 2010. Adsorption of $\mathrm{Zn}^{2+}$ ions onto NaA and NaX zeolites: Kinetic, equilibrium and thermodynamic studies, J. Hazard. Mater., 173, 637-646.

[15] Chen, Y., and chen, N., 2011. Kinetic study of $\mathrm{Cu}(\mathrm{II})$ adsorption on nanosized $\mathrm{BaTiO}_{3}$ and $\mathrm{SrTiO}_{3}$ photocatalysts, J. Hazard. Mater.; 185, 168-173.

[16] Mmanamon, C. M., Burhe, A. M., Holmes, J. D., and Marris, M. A., 2012. Amine-funct. SBA-15 of tailored pore size for heavy metal ads., J. of colloid and interf. Sci. 369, 330-337.

[17] Zhanga, Q., Pana, B., Zhange, W., Lva, L., Wang, X., Wua, J., and Taob, X., 2009. Selective removal of Pb(II), Cd(II), and $\mathrm{Zn}(\mathrm{II})$ ions from waters by an inorganic exchanger $\mathrm{Zr}\left(\mathrm{HPO}_{3} \mathrm{~S}\right)_{2}$, J. Hazard. Mater., 170, 824-828.

[18] Jadhoo, M. M., Palinal L-J., and Bhave, N. S., 2008. Resin. III. Synthesis, characterization, and ion-exchange properties of a 2,2'-dihydroxybiphenyl-formaldehyde copolymer resin, J. Appl. Polym. Sci., 109, 508.

[19] Shin, E. W., Karthi Reyan, K. G., and Tshabatala, M. A., 2007. Adsorption mechanism of cadmium on juniper bark and wood, Bioresur. Technol, 98, 588-594.

[20] Bulut, Y., Tez, Z., 2007. Adsorption studies on ground shells of hazelnut and almond, J. Hazard. Mater.,149, 35-41.

[21] Weber, W. J., Morris, J. C., 1963. Kinetic of adsorption on carbon from solution, Am. Soc. Chem. Eng., 89, 31-59.

[22] Krishanan, K. A., and Anirudhan, T. S., 2002. Removal of mercury(II) from aqueous solutions and chloralkali industry effluent by steam activated and sulphurised activated carbons prepared from bagasse pith: kinetics and equilibrium studies, J. Haza. Mate., 92, 161.

[23] Li, Q., Chai, L., Yang Z., and Wang, Q., 2008. Kin Ap. Su. Sc., 11-24.

[24] Aksu, Z., and Karabbauir, G., 2008. Comparison of biosorption properties of different kinds of fungi for the removal of Gryfalan Black RL metal-complex dye, Bioresource Technol, 99, 77350-7741. 